\title{
E-MONEY DALAM PERSPEKTIF HUKUM EKONOMI SYARIAH
}

\author{
Muhammad Ridwan Firdaus \\ S2 Hukum Ekonomi Syariah UIN Sunan Gunung Djati Bandung \\ Email: own.yamusa@gmail.com
}

\begin{abstract}
ABSTRAK:
Uang sebagai alat tukar dalam kegiatan ekonomi selalu senantiasa berubah, baik bentuk, nilai intrinsik, maupun nilai ekstrinsiknya. Agama Islam sebagai agama yang universal dan sebagai way of life, mengatur gejala-gejala baru yang timbul di masyarakat. Kehalalalan penggunaan uang elektronik masih diragukan oleh masyarakat. Karena wujudnya yang tidak tampak hanya berapa nomor, dan berupa kode digital pada sebuah chip atau server. Tujuan ini bertujuan mencari common value dan posisi uang elektronik. Penelitian dibatasi pada tcash yang dikeluarkan oleh PT. Telkomsel. Hasil penelitian menemukan, bahwa uang elektronik hanyalah merupakan suatu jasa yang ditawarkan penerbit untuk mempermudah dan mengefisienkan proses transaksi ekonomi.

Kata kunci: e-money, hukum ekonomi Syariah.
\end{abstract}

\section{ABSTRACT:}

Money as a medium of exchange in economic activities always changes, both in form, intrinsic value, and extrinsic value. Islam as a universal religion and as a way of life, regulates new symptoms that arise in society. The halal use of electronic money is still in doubt by the public. Because the form that is not visible is only how many numbers, and in the form of digital code on a chip or server. This goal aims to find the common value and position of electronic money. Research is limited to tcash issued by PT. Telkomsel. The results of the study found that electronic money is only a service offered by publishers to simplify and streamline the process of economic transactions.

Keywords: e-money, Sharia economic law.

\section{Pendahuluan}

Allah telah menciptakan manusia dengan segala kesempurnaannya dan menjadikan dia sebagai khalifah di muka bumi. Sebagimana Allah berfirman dalam QS. Al-Baqarah: 30

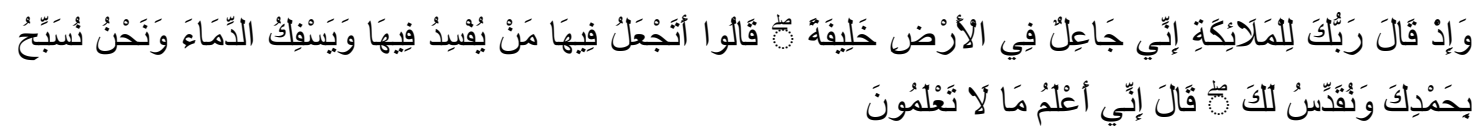

'Ingatlah ketika Tuhanmu berfirman kepada para Malaikat: "Sesungguhnya Aku hendak menjadikan seorang khalifah di muka bumi." Mereka berkata: "Mengapa Engkau hendak menjadikan (khalifah) di bumi itu orang yang akan membuat kerusakan padanya dan menumpahkan darah, padahal kami senantiasa bertasbih 


\section{Tabkím}

Vol. XIV, No. 1, Juni 2018

dengan memuji Engkau dan mensucikan Engkau?” Tuhan berfirman: "Sesungguhnya Aku mengetahui apa yang tidak kamu ketahui.,"

Allah telah menjelaskan bahwa Dialah Tuhan yang menciptakan dan menghidupkan manusia untuk ditempatkan dimuka bumi. "Sesungguhnya Aku hendak menjadikan makhluk yang akan Aku tempatkan di bumi sebagai penguasa. Ia adalah Adam beserta anak-cucunya. Allah menjadikan mereka sebagai khalifah untuk membangun bumi. ${ }^{2}$ Khalifah berasal dari bahasa Arab yang berarti pemimpin. Dengan demikian dalam menjalankan perannya, manusia harus bertindak layaknya seorang pemimpin yang senantiasa menjaga segala sesuatunya berdasarkan aturan yang dilakukan dengan penuh perhitungan dan kesadaran untuk menjaga keharmonisan serta kelestarian dimuka bumi. Firman Allah dalam QS. Al-An'am: 165

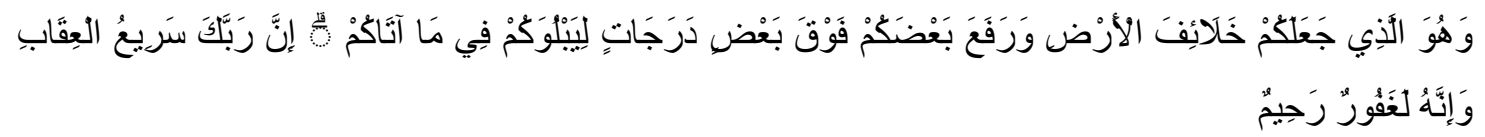

'Dan Dialah yang menjadikan kamu penguasa-penguasa di bumi dan Dia meninggikan sebahagian kamu atas sebahagian (yang lain) beberapa derajat, untuk mengujimu tentang apa yang diberikan-Nya kepadamu. Sesungguhnya Tuhanmu amat cepat siksaan-Nya dan sesungguhnya Dia Maha Pengampun lagi Maha Penyayang. ${ }^{3}$,

Ayat tersebut menunjukkkan bahwa manusia diturunkan ke bumi untuk menjadi penguasa atau pemimpin atas dirinya, keluarga, masyarakat, serta negaranya. Manusia akan diberikan ujian berkenaan dengan rezekinya, dan akan memberikan pahala atau siksa tergantung cara kita menyikapinya.

Aristoteles mengungkapkan bahwa selain seorang pemimpin di dunia, manusia juga merupakan makhluk sosial (zon politicon) yang dalam memenuhi kebutuhan hidupnya baik dari segi sandang, pangan, maupun papan manusia melakukan proses usaha antar sesamanya melalui interaksi sosial yang kemudian disebut dengan kegiatan ekonomi. Kegiatan ekonomi tidak bisa dilepaskan dengan kehidupan manusia karena kegiatan kecil seperti mengolah bahan mentah sehingga menjadi makanan dan memakannya sudah merupakan salah satu bentuk dari kegiatan ekonomi.

Penggunaan uang sebagai alat tukar pada kegiatan ekonomi yang di dalamnya terdapat produksi, distribusi dan konsumsi, merupakan sesuatu yang tidak bisa dilepaskan dari kehidupan manusia saat ini. Keberadaan uang yang terus berevolusi berawal dari nilai intrinsik uang seperti dinar emas kepada nominal atau nilai ekstrinsik uang seperti rupiah. Anggapan mata uang dalam Islam harus selalu berbentuk emas atau perak saja ternyata tidaklah benar. Seperti yang dikutip oleh Nurul Huda dalam bukunya, bahwa ada salah seorang sahabat Rasulullah saw,yaitu Khalifah Umar ra.,

\footnotetext{
${ }^{1}$ Departemen Agama RI, Al-Qur'an dan Terjemahnya (Jakarta: Ditjen Bimas Islam, 2009), h. 6.

${ }^{2}$ M. Quraish Shihab, Tafsir al-Misbah (Ciputat: Lentera Hati, 2000).

${ }^{3}$ Ibid., h. 202.
} 


\section{Tahkím}

Vol. XIV, No. 1, Juni 2018

yang berpendapat bahwa uang sebagai nilai tukar tidak terbatas kepada dua bentuk itu saja. Bahkan dia menyebutkan pernah ingin menjadikan kulit unta sebagai mata uang. Hal ini diakibatkan kesadarannya, bahwa nilai emas dan perak sangat tergantung kepada hukum pasar yaitu hukum penawaran-permintaan. ${ }^{4}$

Nurul Huda juga mengungkapkan pendapat Ibnu Taimiyah, bahwa uang sebagai alat tukar dapat berbentuk apapun serta tidak terikat dengan keharusannya berbahan logam mulia seperti emas dan perak, akan tetapi uang sebagai alat tukar ditentukan oleh adat kebiasaan atau 'urf yang berlaku disuatu tempat atau daerah. Dinar atau dirham sebagai medium of exchange atau wasilah tidak berhubungan dengan apapun, baik dari bahan, bentuk, gambar maupun cetakannya. Akan tetapi fungsi dari tujuan pembuatan mata uang tersebut sebagai alat tukar keperluan manusia dapat dipenuhi. ${ }^{5}$

Melalui berbagai pendapat tersebut dapat dipahami, bahwa fungsi uang hanya sebagai alat tukar semata, sebagai perantara dalam pemenuhan kebutuhan manusia. Uang kertas dan uang logam yang berlaku saat ini disebut juga fiat money atau uang kartal karena kemampuan daya beli mata uang tersebut tidak didasarkan kepada emas, melainkan karena pemerintah menetapkannya sebagai nilai tukar. Jika pemerintah mengganti atau mencabut ketetapan tersebut, maka mata uang itu tidak akan bernilai apapun.

Seiring dengan kemajuan zaman, bentuk pembayaran dengan uang pada hari ini mengarah kepada sesuatu yang lebih praktis dan tidak memiliki wujud sama sekali, hanya berupa kode digital yang berada di server, kartu chip, atau smartphone seseorang yang disebut dengan uang elektronik (e-money) atau mata uang digital (digital currency).

Menurut jenisnya, pembayaran digital (virtual currency) terdiri dari 2 macam ${ }^{6}$ :

1. Uang elektronik atau digital yang sering digunakan pada aplikasi-aplikasi berbasis komputer maupun smartphone seperti Telkomsel Cash, Paytrend, Indosat Dompetku dan beberapa alat pembayaran digital lainnya. Jenis virtual currency ini bersifat tersentralisasi, diatur dan dikelola oleh suatu lembaga maupun perusahaan;

2. Virtual currency yang menggunakan teknologi kriptografi yang biasa dikenal dengan sebutan cryptocurrency dimana untuk setiap transaksi, data akan dilakukan penyandian menggunakan algoritma kriptografi tertentu.

Uang elektronik adalah uang yang dipergunakan dalam transaksi melewati jejaring internet secara elektronik dan sistem penyimpanan harga digital. Dalam uang elektronik terdapat nilai tersimpan (stored-value) atau prabayar (prepaid) dimana terdapat nilai uang yang disimpan dalam suatu media elektronik yang berbasis chip

\footnotetext{
${ }^{4}$ Nurul Huda dan Mohamad Heykal, Lembaga Keuangan Islam Tinjauan Teoritis dan Praktis (Jakarta: Kencana, 2010).

${ }^{5}$ Ibid.

${ }^{6}$ Nurfia Oktaviani Syamsiah, Kajian Atas Cryptocurrency Sebagai Alat Pembayaran di Indonesia, Indonesian Journal on Networking and Security, 2017, h. 53-61
} 


\section{Tahkím}

Vol. XIV, No. 1, Juni 2018

atau server. Nilai uang yang terdapat pada uang elektronik akan secara otomatis berkurang pada saat pengguna melakukan pembayaran. Uang elektronik digunakan untuk berbagai macam jenis pembayaran (multi purpose payment) sehingga berbeda dengan instrumen single purpose seperti yang terdapat pada kartu telepon. ${ }^{7}$

Islam sebagai agama yang sempurna mempuyai aturan yang jelas (manhaj alhayat) yang mengatur semua elemen dalam kehidupan manusia yang bersumber dari Al-Qur'an dan Hadis. ${ }^{8}$ Aturan tersebut dimaksudkan untuk menjamin kebahagiaan serta keselamatan manusia baik di semua aspek diri seperti keselamatan agama, jiwa, akal, harta benda, serta keturunannya atau yang biasa disebut dengan adh-dharuriyyah al-khams atau maqashid al-syari'ah. ${ }^{9}$

Tulisan ini bertujuan menganalisis uang elektronik yang dalam hal ini T-cash yang dikeluarkan PT. Telekomunikasi Seluler (perusahaan Telkomsel) sebagai penyedia jasa layanan seluler dari perspektif syariah Islam.

\section{Makna Uang Elektronik}

Neda Popovska-kamnar berpendapat bahwa uang elektronik merupakan instrumen terbaru dalam sistem pembayaran yang dalam definisi lebih luas, adalah uang yang ditransfer secara elektronik. Akan tetapi untuk mendefinisikan uang elektronik secara lebih kompleks dan tepat merupakan suatu masalah karena hal tersebut merupakan sesuatu fenomena yang dinamis dalam kerangka yang cenderung statis 10

Kemunculan uang elektronik awalnya hanya berbentuk internet banking yang memberikan akses, yang semula terbatas menjadi lebih mudah dan meluas. Internet banking memungkinkan nasabah untuk melakukan transaksi via telepon selular. Penggunaan uang elektronik pada saat itu hanya terdapat di ruang lingkup terbatas yang dalam hal ini adalah nasabah bank dengan nasabah bank yang lain. Akan tetapi trend tersebut berubah seiring dengan kemajuan ilmu pengetahuan di bidang teknologi informasi di era tahun 2008. Hal tersebut menjadi awal mula maraknya transaksi jual beli melalui media elektronik. Uang elektronik yang semula dibatasi oleh kalangan tertentu, kini mempunyai ruang lingkup yang lebih luas. Masyarakat luas dapat memanfaatkan jasa penyedia uang elektronik tanpa harus menjadi nasabah di bank tertentu.

\footnotetext{
7“Uang Elektronik,” 2018, http://id.wikipedia.org/wiki/uang_elektronik (diakses 10 Oktober 2018).

${ }^{8}$ Muhammad Syafi'i Antonio, Bank Syariah: Dari Teori ke Praktik (Jakarta: Gema Insani Press, 2001).

${ }^{9}$ Nuruddin bin Mukhtar al-Khadimi, Ilmu Al-Maqashid Al-Syar'iyyah (Maktabah Al-Ubaikah, 2001).

${ }^{10}$ Neda Popovska-kamnar, 'The Use Of Electronic Money And Its Impact On Monetary Policy', Vol. 1, No.. 2 (2014), h. 79-92.
} 


\section{Tahkím}

Vol. XIV, No. 1, Juni 2018

Uang elektronik bukanlah uang yang dicetak layaknya uang kertas atau deposito. Pembayaran hanya dapat dilakukan terbatas hanya pada nominal uang yang terdapat pada media elektronik tersebut yang sebelumnya telah disetorkan kepada pihak penerbit jasa terlebih dahulu, yang kemudian di top up atau isi ulang apabila saldo pada media elektronik tersebut telah habis. Perbedaan uang elektronik dengan metode pembayaran lainnya seperti single purpose payment, adalah perusahaan yang memberikan jasa uang elektronik dengan orang yang menerima pembayarannya berbeda. ${ }^{11}$ Seperti T-cash yang merupakan uang elektronik berbasis server dan berjenis registered karena menggunakan user ID dan sandi pengguna yang bisa digunakan sebagai alat pembayaran di merchant-merchant yang bekerjasama dengan pihak penyedia jasa. Berbeda dengan kartu kredit yang dikeluarkan suatu bank tetapi pembayaran harus melewati bank tersebut pula.

E-money atau yang biasa disebut dengan stored-value product (SVPs) ${ }^{12}$ juga bukanlah jenis uang baru. Tetapi hanya merupakan suatu produk yang menyediakan jasa akses pembayaran, di mana pengguna menggunakan instruksi yang telah ditentukan oleh perusahaan penyedia produk baik dengan cara di tap, gesek, atau memasukkan akun log in dan kata sandi untuk mentransfer dana dari akun pemilik produk kepada merchant. ${ }^{13}$ Uang elektronik juga dapat mengurangi kebutuhan akan uang tunai kertas, cek, kartu kredit atau debit sebagai alat pembayaran, sekaligus dapat menjadi aset kepemilikan seperti deposito atau obligasi, jumlah uang beredar, bahkan menjadi instrumen pada praktik kebijakan moneter. ${ }^{14}$

Keberadaan e-money diharapkan dapat menjadi solusi pembayaran yang inovatif dan cepat di tempat-tempat yang memang membutuhkan efisiensi durasi waktu pembayaran guna meningkatkan pelayanan seperti pembayaran tol, mini market, food court, dan lain sebagainya,

\section{Karakteristik Uang Elektronik}

Uang Elektronik (electronic money) didefinisikan sebagai alat pembayaran yang memenuhi unsur-unsur sebagai berikut: ${ }^{15}$

1. Diterbitkan atas dasar nilai uang yang disetor terlebih dahulu oleh pemegang kepada penerbit;

2. Nilai uang disimpan secara elektronik dalam suatu media seperti server atau chip;

\footnotetext{
${ }^{11}$ Ibid.

${ }^{12}$ Benjamin Geva and Muharem Kianieff, "Reimagining E-Money," Yearbook of International Financial and Economic Law, University of London, 2002, h. 1-45.

${ }^{13}$ Husnil Khatimah and Fairol Halim, "The Intention To Use E-Money Transaction In Indonesia : Conceptual Framework," Collage of Business, Universiti Utara Malaysia, 2009, h. 115-124..

${ }^{14}$ Diana Hancock and David. B. Humphrey, "Payment Transactions, Instruments, and Systems: A Survey," 1998, h. 1573-1624. Money), 2009.

${ }^{15}$ Bank Indonesia, Peraturan Bank Indonesia No.11/12/PBI/2009 - Uang Elektronik (Electronic
} 


\section{Tahkím}

Vol. XIV, No. 1, Juni 2018

3. Digunakan sebagai alat pembayaran kepada pedagang yang bukan merupakan penerbit uang elektronik tersebut; dan

4. Nilai uang elektronik yang disetor oleh pemegang dan dikelola oleh penerbit bukan merupakan simpanan sebagaimana dimaksud dalam undang-undang yang mengatur mengenai perbankan.

Batas nilai uang elektronik yang dapat disimpan di dalam media elektronik dalam surat edaran Bank Indonesia adalah sebesar Rp. 2.000.000,- bagi yang unregistered dan Rp. 10.000.000,- bagi yang registered dan keduanya memiliki batas transaksi sebesar Rp. 20.000.000,- dalam setiap bulannya. ${ }^{16}$

\section{Kelebihan serta Kekurangan Uang Elektronik}

Maraknya uang elektronik harus dibarengi dengan pemahaman terlebih dahulu kelebihan serta kekurangan yang terdapat pada uang elektronik. Kelebihan uang elektronik:

1. Transaksi cepat dan lancar

2. Tidak perlu terlebih dahulu menabung di suatu bank tertentu;

3. Praktis dan mudah dibawa.

Sedangkan kekurangan uang elektronik:

1. Tidak mempunyai sistem pengaman seperti pin;

2. Sulitnya klaim ketika media elektronik hilang atau rusak, sehingga nominal uang yang terdapat didalamnya tidak dapat diganti oleh pihak penerbit;

3. Belum banyak merchant yang menerima uang elektronik sebagai media pembayaran, apalagi di tempat-tempat tradisional.

4. Mengakibatkan pengguna uang elektronik cenderung boros.

\section{Konsep Harta atau Uang Menurut Pandangan Islam}

Pelaksanaan Islam sebagai way of life ${ }^{17}$ berarti melaksanakan semua kegiatan disegala aspek kehidupan sesuai dengan syariat-syariat Islam, guna mendapatkan kehidupan yang baik di dunia dan akhirat. Allah berfirman dalam QS. al-Baqarah: 29

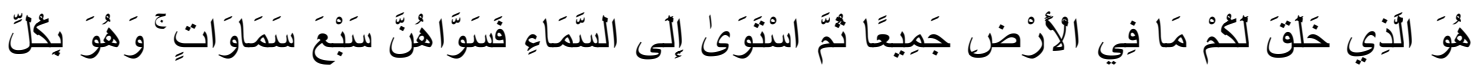

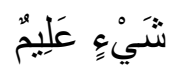
"Dialah Allah, yang menjadikan segala yang ada di bumi untuk kamu dan Dia berkehendak (menciptakan) langit, lalu dijadikan-Nya tujuh langit. Dan Dia Maha Mengetahui segala sesuatu."18 2018.

${ }^{16}$ Bank Indonesia, Peraturan Bank Indonesia Nomor 20/6/PBI/2018 Tentang Uang Elektronik,

${ }^{17}$ Syafi'i Antonio, loc. cit.

${ }^{18}$ Departemen Agama RI, op.cit., h. 6. 


\section{Tahkím}

Vol. XIV, No. 1, Juni 2018

Melalui keterangan di atas, Allah telah menciptakan segala yang ada dilangit dan bumi semata-mata demi kepentingan manusia. Hal tersebut dapat diuraikan sebagai berikut:

1. Allah merupakan pemilik mutlak segala sesuatu, manusia hanya dipercaya untuk mengelola dan memanfaatkan sesuai dengan ketentuan-Nya;

2. Harta atau uang sebagai titipan, perhiasan hidup yang tidak berlebihan, sebagai ujian keimanan, dan hanya sebagai bekal ibadah;

3. Kepemilikan harta harus ditempuh dengan jalan yang halal dan bukan dengan jalan haram;

4. Dalam pencariannya, tidak melupakan, lalai, bahkan meninggalkan ibadah. ${ }^{19}$

Prinsip dasar sistem ekonomi Islam menggambarkan bahwa manusia yang dalam posisinya sebagai khalifah Allah swt. di muka bumi, memiliki hak dan tanggung jawab untuk memiliki dan memanfaatkan apa yang Allah ciptakan untuk kita. Akan tetapi hak memiliki ini terbatas dan sah, sejajar dengan tanggung jawab manusia untuk bertindak sesuai dengan kehendak dan hukum Allah swt.

Kekayaan tidak boleh terkonsentrasikan di tangan sedikit orang saja, dan itu mengharuskan adanya kerjasama antarmanusia dalam pemanfaatannya. Hakikatnya dalam perekonomian, fungsi utama uang merupakan alat transaksi (medium of exchange). Dari fungsi utama tersebut lalu dijabarkan beberapa fungsi yang lain seperti:

1. Uang sebagai pembakuan nilai (standard of value);

2. Uang sebagai penyimpanan kekayaan (store of value);

3. Uang sebagai satuan penghitung (unit of account);

4. Uang sebagai pembakuan pembayaran tangguh (standard of deffered payment). ${ }^{20}$

Perbedaan pandangan Islam yang paling mendasar mengenai uang adalah Islam menggapap uang hanya sebagai media tukar (medium of exchange) untuk mendapatkan barang sehingga kebutuhan hidup dapat terpenuhi. Uang dalam Islam tidak menjadi objek komoditi yang dapat diperjualbelikan dan disewakan guna mencari kelebihan keuntungan darinya. ${ }^{21}$ Penggunaan uang sebagai objek komoditi bisa menjurus kepada riba.

\section{Pengertian Tcash (Registered)}

Tcash adalah layanan uang elektronik dari PT. Telekomunikasi Seluler atau Telkomsel yang digunakan oleh pelanggan Telkomsel maupun non Telkomsel untuk semua transaksi dengan menggunakan aplikasi. Tcash pertama kali diperkenalkan Telkomsel pada tahun 2007 sebagai bagian dari bisnis digitalnya. Namun

\footnotetext{
${ }^{19}$ Syafi'i Antonio, loc.cit.

${ }^{20}$ Huda and Heykal, loc.cit.

${ }^{21}$ Ibid.
} 


\section{Tahbím}

Vol. XIV, No. 1, Juni 2018

perkembangan bisnis Tcash saat itu mengalami tantangan, karena masih rendahnya minat masyarakat menggunakan layanan teknologi finansial. Diawali dengan dorongan pemerintah melalui Gerakan Nasional Non Tunai (GNNT), Tcash pun diperkenalkan kembali melalui peluncuran inovasi pembayaran menggunakan teknologi near-field communication (NFC), yang dinamakan Tcash Tap. Dengan teknologi pembayaran tersebut pelanggan dapat bertransaksi non-tunai di berbagai merchant outlets. Tcash menghadirkan tiga jenis user interface utama yang dapat dipilih oleh pelanggannya sesuai kebutuhannya masing-masing, yaitu: 1 . Melalui sticker NFC Tcash Tap; 2. Kode Akses USSD *800\#; dan 3. Snap QR Code di TCASH Wallet. Dengan jasa yang ditawarkan sebagai berikut ${ }^{22}$ :

\begin{tabular}{|c|c|c|}
\hline & Basic Service & Full Service \\
\hline Saldo maksimum & $\operatorname{Rp} 2000.000$ & Rp 10.000 .000 \\
\hline Maksmum Transaksi. & Rp $20.000 .000 /$ bulan & Rp $20.000 .000 /$ bulan \\
\hline ISi Saldo & $\checkmark$ & $\checkmark$ \\
\hline Eavar Merchant & $\checkmark$ & $\checkmark$ \\
\hline Eell pulsa & $\checkmark$ & $\checkmark$ \\
\hline Eelanja online & $\checkmark$ & $\checkmark$ \\
\hline Eayar Deli di IIP & $\checkmark$ & $\checkmark$ \\
\hline Eerbag Lang & $x$ & $\checkmark$ \\
\hline Tarik Salco & $\boldsymbol{x}$ & $\checkmark$ \\
\hline
\end{tabular}

Penggunaan jasa Tcash diawali dengan mendaftar di aplikasi yang telah disediakan yang kemudian mengisi saldo yang dikehendaki, dan pengguna sudah dapat memanfaatkan fasilitas yang telah di sediakan.

\section{Konsep Uang Elektronik dalam Pandangan Hukum Ekonomi Syariah}

Dari penjabaran-penjabaran yang telah dipaparkan diatas, penulis berpendapat bahwa uang elektronik hukumnya boleh, didasarkan kepada dalil Al-Quran surat AnNisa: 29:

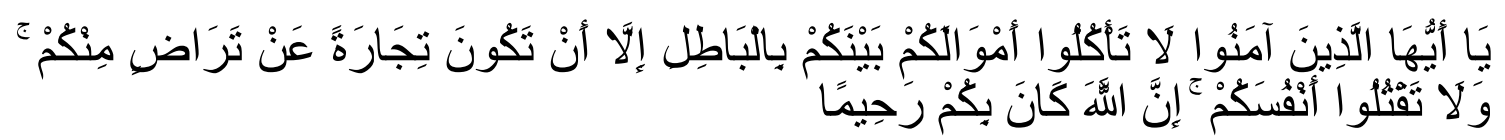

'Hai orang-orang yang beriman, janganlah kamu saling memakan harta sesamamu dengan jalan yang batil, kecuali dengan jalan perniagaan yang berlaku dengan

${ }^{22}$ Sumber dari laman web https://www.tcash.id/about. 


\section{Tahkím}

Vol. XIV, No. 1, Juni 2018

suka sama-suka di antara kamu. Dan janganlah kamu membunuh dirimu; sesungguhnya Allah adalah Maha Penyayang kepadamu. ${ }^{23}$

Dari dalil Al-Quran diatas bahwa manusia boleh bermuamalah dalam bidang ekonomi, asalkan dengan cara yang benar dan tidak dilakukan dengan cara yang salah menurut syara, juga dengan didasari saling ridha meridhai. Dalil dalam bermuamalah ini pun dikuatkan dengan Hadits Rasulullah SAW yang diriwayatkan oleh imam Muslim dari aisyah dan dari Tsabit dari Anas:

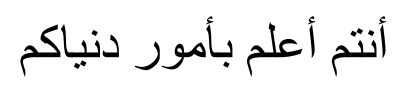

'Kalian lebih mengerti urusan dunia kalian.' (HR. Muslim). ${ }^{24}$

Dalil kehalalan uang elektronik juga dapat didasarkan dengan kaidah fiqh:

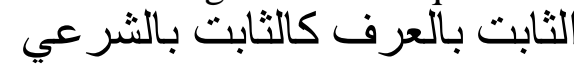

'Sesuatu yang berlaku berdasarkan adat kebiasaan sama dengan sesuatu yang berlaku berdasarkan syara (selama tidak bertentangan denga syariah).'

Dewan Syariah Nasional Majelis Ulama Indonesia telah mengeluarkan fatwa yang berkaitan dengan uang elektronik, dan menyatakan bahwa hukum uang elektronik itu pada dasarnya boleh asal dengan syarat-syarat:

1. Uang elektronik (electronic money) adalah alat pembayaran yang memenuhi unsur-unsur berikut:

a. Diterbitkan atas dasar jumlah nominal uang yang disetor terlebih dahulu kepada penerbit;

b. Jumlah nominal uang disimpan secara elektronik dalam suatu media yang teregistrasi;

c. Jumlah nominal uang elektronik yang dikelola oleh penerbit bukan merupakan simpanan sebagaimana dimaksud dalam undang-undang yang mengatur mengenai perbankan; dan

d. Digunakan sebagai alat pembayaran kepada pedagang yang bukan merupakan penerbit uang elektronik tersebut.

2. Uang elektronik syariah adalah uang elektronik yang sesuai dengan prinsipprinsip syariah. $^{25}$

\footnotetext{
${ }^{23}$ Departemen Agama RI, op.cit., h. 107-108. Arabi, t.th.).

${ }^{24}$ Imam Muslim bin Hajjaj, Shahih Muslim; Hadits-hadits Lengkap (Beirut: Dar Al-Ihya Turats

${ }^{25}$ Fatwa Dewan Syariah Nasional no 116/DSN-MUI/IX/2017 tentang Uang Elektronik Syariah.
} 


\section{Tahkím}

Vol. XIV, No. 1, Juni 2018

\section{Akad yang Digunakan dalam Uang Elektronik ${ }^{26}$}

Akad antara penerbit dengan pemegang uang elektronik adalah akad wadi'ah atau akad qardh. Dalam hal akad yang digunakan adalah akad wadi'ah, maka berlaku ketentuan dan batasan akad wadi'ah sebagai berikut:

1. Jumlah nominal uang elektronik bersifat titipan yang dapat diambil/digunakan oleh pemegang kapan saja;

2. Jumlah nominal uang elektronik yang dititipkan tidak boleh digunakan oleh penerima titipan (penerbit), kecuali atas izin pemegang kartu;

3. Dalam hal jumlah nominal uang elektronik yang dititipkan digunakan oleh penerbit atas izin pemegang kartu, maka akad titipan (wadi'ah) berubah menjadi akad pinjaman (qardh), dan tanggung jawab penerima titipan sama dengan tanggung jawab dalam akad qardh;

4. Otoritas terkait wajib membatasi penerbit dalam penggunaan dana titipan dari pemegang kartu (dana float);

5. Penggunaan dana oleh penerbit tidak boleh bertentangan dengan prinsip syariah dan peraturan pemndang-undangan.

Dalam hal akad yang digunakan adalah akad qardh, maka berlaku ketentuan dan batasan akad qardh sebagai berikut:

1. Jumlah nominal uang elektronik bersifat hutang yang dapat diambil serta dapat digunakan oleh pemegang kapan saja;

2. Penerbit dapat menggunakan (menginvestasikan) uang hutang dari pemegang uang elektronik;

3. Penerbit wajib mengembalikan jumlah pokok piutang pemegang uang elektronik kapan saja sesuai kesepakatan;

4. Otoritas terkait wajib membatasi penerbit dalam penggunaan dana pinjaman (utang) dari pemegang kartu (dana float);

5. Penggunaan dana oleh penerbit tidak boleh bertentangan dengan prinsip syariah dan peraturan perundang-undangan.

Di antara akad yang dapat digunakan penerbit dengan para pihak dalam penyelenggaraan uang elektronik (prinsipal, acquirer, pedagang merchant, penyelenggara kliring, dan penyelenggara penyelesaian akhir) adalah akad ijarah, akad ju'alah, dan akad wakalah bi al-ujrah.

Di antara akad yang dapat digunakan antara penerbit dengan agen layanan keuangan digital adalah akad ijarah, akad ju'alah, dan akad wakalah bi al-ujrah. DSN MUI pun menambahkan aturan mengenai uang elektronik yaitu jumlah nominal uang elektronik yang ada pada penerbit harus ditempatkan di bank syariah, serta dalam hal kartu yang digunakan sebagai media uang elektronik hilang maka jumlah nominal uang

\section{${ }^{26}$ Ibid.}




\section{Tahkim}

Vol. XIV, No. 1, Juni 2018

yang ada di penerbit tidak boleh hilang. Penggunaan uang elektronik memiliki dimensi insani yang dominan ${ }^{27}$ sehingga tidak bertentangan dengan dimensi ilahi dari tujuan syariah.

Bertentangan dengan pendapat Karl Marx yang terkenal bahwa agama adalah salah satu bentuk hasil ekspresi manusia yang tertindas, sehingga menyamakan agama dengan opium, dan menyatakan bahwa untuk mendapatkan kebahagiaan yang hakiki, manusia harus melepaskan sumber kebahagiaan semu yaitu agama ${ }^{28}$, agama Islam merupakan agama menyeluruh yang dinamis, akan tetapi tidak overly flexible, dan agama yang kokoh akan tetapi tidak kaku (rigid), yang merupakan sumber kebahagiaan yang mutlak. Tanpa agama manusia justru akan hampa, dan kehilangan arah, yang berujung kepada kerusakan tatanan kehidupan sosial.

\section{Kesimpulan}

Islam memandang uang elektronik yang merupakan produk dari gejala sosial yang baru, sebagai sesuatu hal yang boleh atau mubah, karena pada dasarnya asal semua hal dalam muamalah itu adalah boleh, asal tetap berada dalam koridor kebenaran menurut syara dan undang-undang. Uang elektronik hanyalah suatu bentuk baru dari uang yang senantiasa berubah. Islam pun tidak menafikan pencarian keuntungan yang diperoleh dari jasa uang elektronik, karena yang dilarang adalah upaya membeli uang dengan uang, tetapi pada e-money ini si pengguna membeli jasa "kemudahan transaksi" yang ditawarkan oleh penerbit. Sehingga penyedia jasa mendapatkan keuntungan dari jasa yang mereka jual, dan pengguna pun mendapatkan kemudahan dari penyedia layanan.

\section{DAFTAR PUSTAKA}

Bank Indonesia, Peraturan Bank Indonesia No.11/12/PBI/2009 - Uang Elektronik (Electronic Money), 2009.

- Peraturan Bank Indonesia Nomor 20/6/PBI/2018 Tentang Uang Elektronik, 2018.

Chiu, Jonathan, and Tsz-nga Wong, 'E-Money: Efficiency, Stability and Optimal Policy', Bank of Canada Working Paper, 2014

Departemen Agama RI. Al-Qur'an dan Terjemahnya, Jakarta: Ditjen Bimas Islam, 2009.

Geva, Benjamin, dan Muharem Kianief. "Reimagining E-Money," Yearbook of

\footnotetext{
${ }^{27}$ Lihat La Jamaa, "Dimensi Ilahi dan Dimensi Insani dalam Maqashid al-Syari'ah,” Jurnal AsySyir'ah, Vol. 45, No. II, Juli-Desember 2011, h. 1251. 1957).

${ }^{28}$ Karl Marx and Friedrich Engels, On Religion (Moscow: Foreign Languages Pub. House,
} 


\section{Tahkim}

Vol. XIV, No. 1, Juni 2018

International Financial and Economic Law, University of London, 2002, 1-45

Hajjaj, Muslim bin. Shahih Muslim; Hadits-hadits Lengkap, Beirut:Dar Al-Ihya Turats Arabi.

Hancock, Diana, dan David. B. Humphrey. "Payment Transactions, Instruments, and Systems: A Survey," 1998.

Huda, Nurul, dan Mohamad Heykal. Lembaga Keuangan Islam Tinjauan Teoritis Dan Praktis, Jakarta: Kencana, 2011.

Khatimah, Husnil, and Fairol Halim, "The Intention To Use E-Money Transaction In Indonesia: Conceptual Framework," Collage of Business, Universiti Utara Malaysia, 2009.

Jamaa, La. "Dimensi Ilahi dan Dimensi Insani dalam Maqashid al-Syari'ah," Jurnal Asy-Syir'ah, Vol. 45, No. II, Juli-Desember 2011.

Marx, Karl, dan Friedrich Engels, On Religion, Moscow: Foreign Languages Pub. House, 1957.

Mukhtar al-Khadimi, Nuruddin bin, Ilmu Al-Maqashid Al-Syar'iyyah, Maktabah AlUbaikah, 2001.

Popovska-kamnar, Neda. "The Use Of Electronic Money And Its Impact On Monetary Policy," Vol. 1, 2014.

Shihab, M. Quraish, Tafsir Al-Misbah, Ciputat: Lentera Hati, 2000.

Sudjana, Nana, Tuntunan Penyusunan Karya Ilmiah, Bandung: Sinar Baru Algesindo, 2009.

Syafi'i Antonio, Muhammad, Bank Syariah: Dari Teori ke Praktik, Jakarta: Gema Insani, 2001.

Syamsiah, Nurfia Oktaviani, "Kajian Atas Cryptocurrency Sebagai Alat Pembayaran Di Indonesia," Indonesian Journal on Networking and Security, Vol. 6, 2017.

'Uang Elektronik', $2018<$ https://id.wikipedia.org/wiki/Uang_elektronik>

Fatwa

Dewan Syariah Nasional no 116/DSN-MUI/IX/2017 tentang Uang Elektronik Syariah Website

web https://www.tcash.id/about. 